Revisla da ANPOL/, n" 4, p. 157-168, jan./jun. 1998

\title{
MITO EM MOSAICO: ORFEU E QUEDA EM TEXACO
}

\author{
Luiz Fernando Ferreira Sá*
}

\begin{abstract}
RESUMO: O propósilo deste estudo é mostrar como o contexto da oralidade e o evento de desapropriação sofrido por diferentes povos pos-coloniais possibilitaram que Palrick Chamoiseau escrevesse Texaco como uma narraliva duplamente codificada em perda e queda. Se por um lado Chamoiseau relembra o milo de Orfeu alravés do personagem Esternome Laborieux para dilatar sua diç̧ão literária, por outro lado, a descida de seu Orfeu dos morros coloniais assume a possibilidade de redençäo na geografía especular e plural da cidade. Os esforços do escritor, seu Orfeu, e leitor para manejar as geografias invisiveis recriadas diante de seus olthos são tentativas de visōes de descentramento das realidades subterrâneas da linguagem.
\end{abstract}

PALAVRAS- CIIAVE: literalura pós-colonial; literalura e cultura latino-americanos; oralidade; milo; Orfeu.

"Espaço literário: uma geografia imaginária, cheia de sinais secretos, que vão nos guiando por um terreno impossível de visualizar." Maurice Blanchot

A pulsão de morte está subjacente na dialética do senhor e do características superficiais, os seus atos e símbolos legitimadores até chegar ao ponto de querer o seu corpo e tudo aquilo que o compraz. Se tomarmos esta dialética e metaforizarmo-la em relação ao leitor e à sua leitura, teremos então uma relativa dissimulação do texto frente às diver-

* Universidade Federal de Minas Gerais - UFMG.

1 O termo "pulsão de morte" é usado no presente texto como sendo coextensivo à rememoração e à historização (Lacan 1988:256). Efetivamente, o termo pöe em causa tudo o que existe e "é igualmente vontade de criação a partir de nada, vontade de recomeçar" (Lacan 1988:260). Também relacionado com palsão e dialética, temos o "silencioso disparo diáćtico" na geografia lezamiana (Lima 1988:170). 
Sí, Luís Fernando Ferreira de. Milo em mosaico: Orfeu e queda em Texaco.

sas tentativas de penetração do olhar do leitor. A missão de leitura é de tornar o texto aparente, dissolvê-lo, no sentido de the conferir uma presença, uma personalidade que é na maioria das vezes a nossa cara desaparecida (Iser 1979:85-100). Sabe-se bem que o texto em si mesmo tem sua própria vida, mas é através de um sopro inicial do leitor que o texto, ofuscado no mundo material, responde com a sua ressurreição. $\mathrm{O}$ interrelacionamento significativo das palavras dentro de um texto qualquer é sempre ocupado, habitado por vozes tanto do leitor; sua presença e personalidade, como do escritor, sua pluralidade paradigmática e transtextual (Iser 1978). Assim sendo, o sema de grau zero não passa de uma ilusão de ótica e o discurso literário é invadido, absorvido e transformado por uma gama imensa de outros textos e olhares.

Se o leitor é o senhor e o texto o seu escravo, a topografia evocada é mutante e perversa. Seguindo o mesmo raciocínio, no caso de tentarmos apreender a rede de sentidos no conjunto de enunciados poéticos, teríamos como dizia Platão: "caído no labirinto, quando, pensando que já tivéssemos chegado ao fim, ainda nos encontrássemos, por assim dizer, após haver dado uma volta sobre nós mesmos, no início de nossa busca, c tão pouco avançados quanto estávamos ao começar a nossa investigação". 2 Privilegiando a figura abstrata do espaço labiríntico, descentrado c cheio de "mistérios", não é impossível que Patrick Chamoiscau em seu livro Texaco tenha começado a escrever com o olhar de Orfeu.

A escrita é dilatada em todas as direções, há um tumulto de palavras para alimentar um gênero órfico de vida. As palavras cantadas-escritas por Orfeu desconstroem o discurso dos outros: morrer em face do mundo, em face da cidade, para enclausurar a escrita do espaço político vigente. Daí edificar um outro espaço, um discurso vertiginoso, o qual já foi totalmente embriagado pelo mel da noite (Detienne 1989:85,89). A narrativa de Chamoiseau também pode ser lida como uma nova versão do

2 Patão, Eulidemo, 291 b. Raciocínio em círculo que serviria tanto para un encaminhamento dialético, quanto como metálora do próprio pensamento mítico (Detienne 1989:22). 
Revista da ANPOLL, n" 4, p. 157-168, jan./jun. 1998

mito de Orfeu, pois quando este desce ao I lades para resgatar Eurídice, a arte é o poder pelo qual a noite é transgredida (Blanchot 1955:227). "Eurídice é o instante em que a essência da noite se aproxima a outra noite" (Blanchot 1955:227), noite esta que, pela força da arte, o recebe intimamente $\mathrm{c}$ lhe outorga a satisfação de um desejo. Orfeu desce em direção a Eurídice e ela é o extremo que a arte pode atingir: plano superposto do desejo, da morte e da noite no mais subterrâneo dos mundos.

Se a escrita de Chamoiseau é órfica, pois mora eternamente no seio da morte e é cativa de uma busca que deve ser paciente e indireta, então Esternome Laboricux, personagem germinativo e provavelmente geratriz de toda narrativa referente ao bairro de Texaco, reverberará a força deste mito em relação à busca do não-encontrável e da "crrança" que constitui o seu ser. Esse personagem simboliza uma luta sempre idêntica e sempre recomeçada para explorar os valores do centro, mas ronda ele próprio o centro inatingível e enquanto busca, ele mora nos infernos. A Esternome não só é infligido o ato purgativo de ter vivenciado o inferno na casagrande, como também, o tempo lúgubre e sulfúreo dos morros.

A catábase de Orfeu-Esternome é a do tipo tradicional, xamânico: o iniciado morre aparentemente e na contemplação do além, encontrando-se, torna-se detentor do saber e dos mistérios, nos quais procurará orientar seus seguidores. Esternome, aquele que mantém uma ação na justiça como defensor ou aquele que é contituído do éter primordial do tempo mítico, discursa de uma maneira espantosa (ele não tinha inicialmente o dom da retórica) contra os "estrabalhadores" pagos que vão trabalhar na fazenda. Orfeu-Esternome é xamã e profeta, cle ouve o Noutéka dos morros: uma espécie de nós mágico, mentôs, as forças - "na verdade, Sophie minha Marie, cu mesmo, que a recebi, sei que liberdade não se concede, não deve ser concedida. Liberdade concedida não liberta a alma ..." c chega mesmo a prever o futuro após a abolição - "repetia meu Esternome sem entender muito porquê, mas já se preparando para as desilusões" (Chamoiseau 1994:82,99). Não obstante, Esternome se solidarializa com 
SÁ, Luís Fernando Ferreira de. Milo em mosaico: Orfeu e queda em Texaco.

Orfeu em relação ao seu grande inimigo, a impaciência: necessária porque mantém aceso o descjo, perigosa porque Eurídice-Ninon não pode ser olhada face a face, como um verdadeiro objetivo $;^{3}$ Esternome liga Ninon à idéia de liberdade e prenuncia: "liberdade não é graviola na ponta do galho! Vocês têm que arrancá-la ... Quanto aos outros, os amantes de estrelas, os negros obstinados como Ninon, a transportarem seus sonhos como quem arrasta a própria sombra" (Chamoiscau 1994:94,113), ou seja, Eurídice-Ninon-Liberdade que se transforma em sombra para sempre no Hades.

Se Chamoiseau teria feito uso do mitismo de Lévi-Strauss, um mecanismo para conferir a uma história um alcance simbólico maior; ou se teria cle invencionado uma história memória para delinear o originário da cidade, extrapola o escopo deste trabalho. Contudo, a paisagem mitológica de Texaco forja um cortejo de emoçôes que é um dos aspectos maiores na relação de cada um dos personagens do livro com eles mesmos e com a organização do espaço. Assim, a paisagem se metamorfoseia numa mitologia em relevo, cujo menor detalhe desvela uma ação heróica, a injunção de um silêncio ou a supressão sonora e violenta de um interdito (Detienne 1989:47,48). Chamoiscau, como Orfeu, escolhe a escrita plural tão profunda quanto a renúncia ao mundo dos outros, aos valores políticos e religiosos da cidade.

Com efeito, a escrita órfica como sinal eficaz de alteridade triunfa sobre a morte e o esquecimento, força o senhor do l lades, a própria noite, a irromper nos fragmentos da memória para depois unificá-los (Eliade 1963:108,120,121). Orfeu-Esternome desce ao inferno, Saint-Pierre cm chamas, e vagueia à procura de sua Eurídice-Ninon:

Foi cercado por incêndios repentinos, agarrado por gretas que emitiam fumarolas.

Sobre ele, a cinza endurecia um cimento que seus gestos faziam desmoronar:

3 Perrone-Moisés se utiliza apenas da analogia entre Orfeu e impaciência nas bases também de umn nãovisível: "todos buscam sempre o não-encontrásel, todos erram e esse erro (essa errança) constitui o seu ser" (1978:90). 
Revisla da ANPOLL, n $\mathrm{n}^{\circ}$ 4, p. 157-168, jan./jun. 1998

Aureolado por essa pocira, parecia mais pálido que uma assombração. $\Lambda$ pedra e as pessoas se haviam misturado. Dos muros erguiam-se mãos endurecidas que não tinham mais dedos. Peles alimentavam a fogueira dos grandes móveis. Logo, Ninon passou a estar em cada canto. Em cada seio esmagado, em cada corpo. fumegando, em cada fogucira. Então meu Esternome perdeu um quarto de sua razão. Pôs-se a gritar como um louco e a correr em todos os sentidos por SaintPierre carbonizada. Terrível combate... (Chamoiscau 1994:138).

Eurídice-Ninon morreu ou talvez se tornou presa fácil para a sedução do senhor da mansão do Hades. O morro parou, tudo se esqueceu. Catábase de uma ordem ainda maior que Chamoiseau atira aos habitantes do morro por meio de seu Orfeu: olhos sem olhar.

O mito de Orfeu nas mãos de Chamoiscau oferece seus conjuros e seus enigmas com um rosto desconhecido, o mito-núcleo foi reclaborado literariamente e criou-se assim uma variante. Uma das histórias inventadas por Esternome para contar, aceitar o sumiço de Ninon é que esta havia sido enfeitiçada e posteriormente afogada pelo canto de uma sercia. Porém, mesmo estando por perto para testemunhar tal cena, Esternomo se protegeu da música por meio de um reflexo. Na expedição dos Argonautas, Orfeu salvou a todos do canto das sereias com sua lira e sua voz (Cuthric 1952:15,27,28). Nesta variação, o tecido mitológico é aprofundado com referências dissimuladas, acrescidas pelo próprio devir da escritura, o Orfeu negro sabe que "a felicidade, na lembrança, torna-se melancolia ou pesada carga de tristeza" (Chamoiseau 1994:144), talvez o melhor seria mesmo o esquecimento. Na versão fidedigna que explica o sumiço de Ninon, Chamoiseau faz refletir uma referência para somar à paisagem uma dimensão mítico-religiosa: o Músico-cão, cujas músicas obsediantes seduziram Ninon, pode ser transmutado na figura do demônio.

Sabe-se bem que o mito conta uma história sagrada, ele descreve um acontecimento ocorrido no tempo fabuloso do princípio (Eliade 1963:11). Com essas irrupções do sagrado no mundo, temos então uma acumulação efetuada por Chamoiscau no momento em que ele reinventa o mito de Orfeu e o intercruza com o mito da queda. Qual dos dois mitos 
SÁ, Luís Fernando Ferreira de. Mito em mosaico: Orfeu e queda em Texaco.

emprestou mais graça às façanhas da narrativa é sem dúvida uma questão secundária neste caso. Entretanto, o que se deve sublinhar é o fato de que o músico que seduz Ninon é o cão: Cérbero ou o próprio demônio. A voz melíflua da serpente-cão persegue e vexa a sua vítima fazendo com que ela desça de bom grado aos infernos.

Outro exemplo de mito em mosaico se dá no caso de Thérésa-MaricRose à espera de seu marido às portas da ilha-prisão:

Depois, sem esperar, sentou-se no canto esquerdo da porta. Encontraram-na ali,
quase como uma estátua de sal, quando (séculos de tempos mais tarde) uma cinza
de perfume titilou a memória dos cérberos e trouxe-lhes a lembrança distante
daquela senhora que havia falado com algum deles ... (Chamoiseau 1994:201).

Já no mito de Orfeu, este olhou para trás, transgredindo o tabu das direções - a esquerda é o encontro do mal, do caos, das trevas e para trás a hamartíai. Orfeu perdeu Eurídice pela segunda vez dada a impaciência de seu olhar. Análogo é o caso em Cênesis da esposa de l_ot que desobedece aos dois anjos de Javé e olha para trás na sua fuga de Sodoma e Gomorra. Ela foi transformada cm coluna de sal, símbolo de purificação, esterilidade e contrato social (Brandão 1992:142-146). Na associação destes dois mitos, as similitudes são reveladas ao lado de gigantescas diferenças. Tal procedimento espelha a figura-chave do devir americano, ou seja, uma retomada do mundo órfico-mediterrâneo cuja orientação se encontra no irreal (Lima 1957:37). O entrevisto preside não somente a narrativa de Chamoiseau, como também guia o processo cm mutação da expressão americana - criam-se fatos pelo espelho da imagem. A América que se fundou numa visão utópica da Europa e com uma gencalogia voltada para trás.

A mitologia em Chamoiseau transforma-se às vezes $\mathrm{cm}$ mitografia, pois ela se escreve, toma forma pela escuta, recebe scus traços de um olhar pertinente e delimita-se em relação aos gêneros do maravilhoso, das histórias paradoxais; as narrações chamadas de ficção ou de história verdadei- 
Revista da ANPOLL, n" +, p. 157-168, jan./jun. 1998

ra, mesclam memória, dever-ser e irrealidade. Todos os trabalhos em volta da reconstrução dos barracos destruídos têm um poder de evocar a eventualidade de mitologizar. Tão familiar à tradição oral, acentua-se aqui, o ponto virtuoso da fórmula deslocada da repetição: "já na noite seguinte voltaríamos a construir, com destroços enriquecidos (dizia Ti-Cirique) pelas constâncias de Sísifo e pela invencibilidade do próprio Fênix" (Chamoiseau 1994:297). Há provavelmente um excesso no propósito e este assemclhase sensivelmente ao mito de Orfeu. Quando Orfeu tange sua cítara e canta com sua voz divina suas dores pela perda de Eurídice, I lades e Perséfone se comovem pois além de outros feitos, o rochedo de Sísifo deixou de oscilar. Se a re-petição não voltar a tomar lugar, se não tivermos que carregar a mesma pedra para o mesmo topo da montanha, fica-nos o alento da reconstrução, da re-criação.

A maneira de aproximação do fato americano ao demonismo moderno ou ao descenso aos infernos é uma sutil ironia ao complexo do americano de acreditar que sua expressão não é uma dimensão alcançada e sim, mais um problema a ser resolvido. O plasma da autoctonia é igual para todos (Iima 1957:62), caso contrário podemos ser acusados de cegueira. A escrita de Orfeu em Chamoiseau incorpora vorazmente tal discussão à medida que Esternome-Orfeu ao constatar a perda de sua anima, Eurídice-Ninon, é levado à imagem-idéia através de Idoménéc. I-onge de ser desmembrado pelas mulheres Trácias e posteriormente tornar-se oráculo, o Orfeu de Chamoiseau recupera o anscio do americano de ser apesar de não ser ainda. Esternome casa-se pois com Idoménée: uma cega com irmã gêmea que simbolizaria o errante, o lado dionisíaco.

Este casamento apolínco do americano com uma tradição cega cuja irmã é tirânica e desprimorosa, longe de ser politicamente correto, é uma transposição do que ocorreu também com o culto órfico. Os gregos como tantos outros não accitaram que a culpa é sempre de responsabilidade individual e que por cla se paga aqui (Cuthric 1952:148-157); não accitaram a idéia de quem não conseguir purgar-se nesta vida, pagará por 
SÁ, Luís Fernando Ferreira de. Mito em mosaico: Orfeu e queda em Texaco.

suas faltas no além, até a catarse final. Essa catarse final poderia muito bem ser uma anamnesis historiográfica que faria com que o homem (americano) penetrasse profundamente em si mesmo. O esforço para conservar a memória dos acontecimentos coṇtemporâneos e o desejo de conhecer o mais acuradamente possível o passado da humanidade se ligaria à imagem da América numa fábula intertextual. Assim sendo, desembocaríamos num autêntico tempo primordial, em que os homens estabeleceram os seus comportamentos culturais sem dívidas a pagar ou cegueiras a serem curadas.

Numa época em que o espaço tem se tornado o parâmetro mais espetacular adotado pelas análises literárias, Texaco de Patrick Chamoiseau se reproduz numa geometria fantástica e se situa entre o infinito e o elementar, imagens espaciais de multiplicação inumerável e redução extrema em labirintos enigmáticos. Labirintos e espelhos são outros emblemas da duplicidade que marca a vertigem do pensamento mitológico e americano. Cabe ao próprio homem americano nomear, afinal, numa dicção controladamente literária e numa polifonia dodecafônica e barroca, o ponto de fuga ou fusão dessas geografias invisíveis (Lima 1957:160-186). Se Esternome-Orfeu não se deu conta, ao menos sua filha, Marie-Sophie, foi além da coisa minuciosamente cartografada e descobriu que no momento preciso da morte, essa vasta confusão de linhas é a imagem de nossa cara. Ambivalente e nostálgica, a personagem em questão prefere se calar temporariamente mas seguir em frente, face tal frêmito de reconhecimento.

Grande parte da história de Texaco representa um universo fantasmático-maravilhoso coagulado no espaço geográfico das Antilhas, onde, sob a autoridade de Marie-Sophie e o encadeamento textual do Marcador de Palavras, se desenrola o espetáculo vivo de uma maquinaria igual à natureza, de uma morte tão impressionante quanto uma vida. A morte de Esternome Laborieux, o negro de sapatos, é envolta em mistérios; esta descida ao mundo de baixo é bloqueada pela escrita de Chamoiseau que nada mais é que uma exaltação à vida, misturando-a novemente à 
morte. O leitmotiv infernal de Téxaco acumula o fantástico-maravilhoso e força-nos a accitá-lo como verossímil. Nas mãos da memorialista favelada, o artificial imita o real, tanto quanto duplica-o e às vezes supera-o. MaricSophie, com destreza e habilidade no seu crioulo rabelaisiano, pôs o bizarro da morte - da prisão dos morros - em relação com seu diferente: a vida, o movimento. Basta que esta relação de opostos se ponha a funcionar, a produzir efeitos, para que seja constituída como verossímil.

Dentro desses aspectos complementares de vida e morte, insere-se o discurso do mito, ou seja, o mito simultaneamente dentro e além da linguagem; o mito integrante da língua (crioula). O caráter atemporal do mito, que faz parte de uma estrutura permanente que dialoga com o passado, presente e futuro, ajuda a precisar a ambigüidade entre geografias longínquas e ao mesmo tempo radicalmente próximas: apocalipse e redenção na vivência metafórica para liberarem a humanidade e criarem o novo estatuto da cidade, a Nova Jerusalém. Quando os morros descem para a outra cidade, Esternome-Orfeu resmunga com o paradoxo de sua língua:

É isso é uma cidade? E olhava as próprias mãos presas na ternura das mãos dela. Idoménée perguntava $O$ que é a Cidade, Ternome? Ele, douto como um leigo, exagerava: a Cidade é um abalo. Um vigor. Ali tudo é possível e tudo é cruel. A Cidade nos leva e nos transporta, jamais nos abandona, mistura-nos com seus segredos que vêm de longe. Aos poucos, captamos esses segredos, sem jamais entendê-los. Então, nós os contamos para os que desceram dos morros e que pensam que entendemos do riscado: mas a Cidade apenas nos engoliu, sem realmente se explicar: Uma Cidade são os tempos reunidos não apenas nos nomes, nas casas, nas estátuas, mas no não-visível (Chamoiseau 1994:157).

Se Esternome-Orfeu inverte o olhar, a cidade torna-se uma terra descoberta: a própria redenção ao alcance de suas mãos. Caso contrário, a cidade é instável e, como sua Eurídice, não mais visível. Em suma, como preconiza Lévi-Strauss, "nada se assemelha mais ao pensamento mítico que a ideologia política. Em nossas sociedades contemporâneas, talvez esta tenha se limitado a substituir aquele" (1975:241). Ora, o mito se 
Sí, tutús Fernando Ferreira de. Mito em mosaico: Orfeu e queda em Texaco.

define não só através da língua, mas simultaneamente através desta e do discurso de poder (político) que constitui e constrói a narrativa da cidade.

Patrick Chamoiscau, a meu ver, não re-constrói o mito de Orfeu ao interligá-lo com o mito bíblico da queda ou com toda a mitologia referente ao mito da memória e do esquecimento: tempos e nomes reunidos. Sem dúvida não devemos em momento algum beber das águas do Letes para nos lembrarmos de quem éramos e nem mesmo para esquecermos quem poderemos ser. $\mathrm{O}$ esquecimento pode não mais simbolizar a morte, mas quiçá o retorno à vida. Se por um lado a nossa história começa com uma desapropriação, um desalojamento, por outro lado, não somos bastante sutis para nos apercebermos do escoamento provavelmente absoluto do devir. As geografias citadinas estão ainda por ser construídas no entrever das diferentes linguagens.

Linguagens tão diferentes quanto a antropogonia e a cosmogonia. A antropogonia, o mito do nascimento do homem, e até mesmo do sujeito mítico-histórico, é muito mais importante no Orfismo do que a cosmogonia. E no caso da América Latina cuja história começou com uma experiência desalentadora de deslocamento geográfico e cultural, é preciso saber o que era antes e o que é agora. Numa antropogonia órfico-americana, "talvez então retorne o sujeito, não como ilusão, mas como fïcção ... inventar uma última ficção, das mais raras: o fictício da identidade". " Se retomarmos a "farsa" (analogia) entre o senhor e o escravo dos parágrafos iniciais, teremos que do lado dos dominados não há nada, nchuma ideologia ou imaginário fecundante, senão precisamente toda a tradição que somos obrigados a tomar de "empréstimo" às culturas que nos dominam (Barthes 1973:45). Faz-se necessário distanciarmos de nós mesmos para examinar os limites e des-ordenação do Hades conhecido por Orfeu e admitir que o prazer do devir é um neutro; em outras palavras, a forma mais perversa do demoníaco. Referente a demoníaco c a diferentes olhares, temos como apreciação crítica de uma releitura de L_ezama: esta

4 B.RTTIES, Roland. O prozer do kexto. São Paulo: Perspectiva, 1973. p1. 80,81. 
Revisla da ANP(OL/, $\mathrm{n}^{\circ}$ +, p. 157-168, jan./jun. 1998

não se fixa no que está atrás do poema (as múltiplas lontes e influências), mas no que tem à frente, ou seja, a modernidade; cnlatizando sutilmente o imaginário 'plutônico' que o anima, orientando, assim, o texto para o cixo crítico-interpretativo que atravessa todo o ensaio: o fato americano como expressão do 'demonismo' moderno" (Lima 1957:97).

É neste sentido que Esternome-Orfeu se transforma num "neutro", a figura do devir do americano, e que a escrita de Chamoiseau é "demoníaca", pois constante e simultancamente olha para trás e para frente. Clivagem e perversão no fictício da identidade, o homem (americano) deve interpretar com paixão as realidades subterrâneas da linguagem.

ABSTRACT: The purpose of this study is to show how the context of orality and the event of disapropriation suffered by different post-colonial peoples have enabled Patrick Chamoiseau to write Texaco as a double encoding narrative of both loss and fall. If on the one hand Chamoiseau recalls the myth of Orpheus through his character Esternome Laborieux to dilate his literary diction, on the other hand, his. Orpheus's descent from the colonial slums uphill assures the possibility of redemplion in the spectacular geography of the city: The efforts of writer; his Orpheus, and reader to manage the invisible geographies recreated before their eyes are altempts at decentered visions of the underwordly realities of language.

KEVWORIDS: post-colonial literalure; orality; myth; Orpheus

\section{BIBLIOGRAFIA}

BARTIIES, Roland. O prazer do texto. São Paulo: Perspectiva, 1973.

BI ANCI IOT, Maurice. L'espace liuléraire. Paris: N. R. F. 1955.5.

BRANDÑO, Junito de Souza. Mitologia grega. Petrópolis: Vozes, 1992.

СH人MOISENU, Patrick. Texaco. São Paulo: Companhia das Icetras, 1994.

DETIENNE, Marcel. A escrila de Orfeu. Rio de Janeiro: Jorge Zahar; 1989.

ELIADE, Mircea. Mito e realidade. São Paulo: Perspectiva, 1963. 
SÁ, Luís Fernando Ferreira de. Mito em mosaico: Orfeu e queda em Texaco.

GUTHRIE, W. K. C. Orpheus and Greek religion. Princeton: Princeton University Press, 1952.

ISER, Wolfgang. The act of Reading: a theory of aesthetic response. Baltimore: The Johns Hopkins University Press, 1978.

A interação do texto com o leitor: In: JAUSS, I lans Robert et al. A Lileralura e o leilor: textos de estética da recepção. Sel., trad., introd., Luiz Costa Lima. Rio de Janciro: Paz e Terra, 1979. p. 83-132.

LACAN, Jacques. O seminário: a ética da psicanálise. Rio de Janeiro: Jorge Zahar; 1988.

LÉVI-STRAUSS, Claude. Antropologia estrutural. Rio de Janeiro: Tempo Brasileiro, 1975.

LIMA, Lezama. A expressão americana. São Paulo: Brasiliense, 1957.

PERRONE-MOISÉS, Leyla. Texto, crítica, escritura. São Paulo: Ática, 1978. 


\section{A OBRA OUVINTE}

Marcos Falchero Falleiros*

RESUMO: Grande Serläo: Veredas dialoga com a fala alravés da escula pelo texto, cuja frontalidade cria fisicamente o exterior de fiente para a página, no ambiente real de uma consciência, onde o leitor magicamente tem que entrar para participar do abraço entre forma literária erudita e cultura popular sertaneja, numa encruzilhada problemálica.

PAldVRAS-CIIAVE: Guimarães Rosa, Grande Serlão:Veredas; literalura e oralidade; cullura erudita e cultura popular; formas brasileiras.

7 antas vezes não somos despertados por Riobaldo quando

d cle nos chama à tona do texto com o apelativo "o senhor"? Mas, já desde a primeira linha, sabemos, que este senhor, que não fala, não somos nós, os que lêem, apesar de, num espaço fraterno ao dele, estarmos, também silenciosos, de frente para o texto. É pelo ouvido, "tiros", que "o senhor" casualmente aparece, ganha existência como personagem oculto c ouve a narração de uma longa história, quando, regida pelo jogo casual entre memória e reflexão, afeto e realidade, cla própria toma corpo no desembocar do seu último lance desnecessário do acaso, sua matéria e matéria da vida, "Nonada" c "Travessia", como o nascimento e o percurso de um rio.

É um personagem ausente daquele mundo: um homem da civilização: por exemplo: um escritor. Recebemos o livro no mercado como um produto do capitalismo. Ninguém lê suas histórias no Crande Sertão e a concepção subjacente à obra do acaso é a de que o homem é quem faz a história, a partir das circunstâncias em que o tempo jogou seu estar-nomundo.

* Universidade lederal do Rio Grande do Norte - UFRN. 